\title{
Management of preterm labor: atosiban or nifedipine?
}

This article was published in the following Dove Press journal:

International Journal of Women's Health

14 May 2010

Number of times this article has been viewed

\section{Roel de Heus \\ Eduard J H Mulder \\ Gerard H A Visser}

Department of Woman and Baby, University Medical Centre Utrecht, The Netherlands
Correspondence: Roel de Heus Department of Woman and Baby, University Medical Centre Utrecht, KJ.02.507.0/PO Box 85090, 3508 AB Utrecht, The Netherlands $\mathrm{Tel}+3 \mathrm{I} 624732630$

Fax +3I 302505320

Email r.deheus-2@umcutrecht.nl
Abstract: Preterm birth is strongly associated with neonatal death and long-term neurological morbidity. The purpose of tocolytic drug administration is to postpone threatening preterm delivery for 48 hours to allow maximal effect of antenatal corticosteroids and maternal transportation to a center with specialized neonatal care facilities. There is uncertainty about the value of atosiban (oxytocin receptor antagonist) and nifedipine (calcium channel blocker) as first-line tocolytic drugs in the management of preterm labor. For nifedipine, concerns have been raised about unproven safety, lack of placebo-controlled trials, and its off-label use. The tocolytic efficacy of atosiban has also been questioned because of a lack of reduction in neonatal morbidity. This review discusses the available evidence, the pros and cons of either drug and aims to provide information to support a balanced choice of first-line tocolytic drug: atosiban or nifedipine?

Keywords: atosiban, oxytocin receptor antagonist, nifedipine, calcium channel blocker, preterm birth, tocolytic drugs, preterm labor

\section{Introduction}

Preterm birth is responsible for approximately $75 \%$ of all neonatal deaths and $50 \%$ of childhood neurological morbidities. ${ }^{1,2}$ Preterm birth is also associated with both high immediate and long-term costs after discharge from the hospital. ${ }^{3}$ Infants born at less than 28 weeks spend 85 times as long in hospital as full-term babies in the first 5 years of life, with substantial healthcare costs. Over recent decades, the frequency of preterm birth in most Western countries seems to be increasing rather than decreasing. ${ }^{4,5}$ This increase cannot be explained by an increase in assisted conceptions, multiple pregnancies and elective deliveries. Perinatal death and morbidity are not only strongly related to early gestational age but are also related to whether or not steroids have been administered antenatally and the preterm infant has been transferred to a tertiary care centre in utero or ex utero. ${ }^{6}$ Therefore, postponing delivery for 48 hours in order to allow maximal effect of maternal parenteral steroid administration and transportation of the mother to a center with neonatal intensive care unit (NICU) facilities are the primary indications to treat women with tocolytic drugs diagnosed with a threatening preterm delivery. However, tocolytic drugs used for inhibition of acute preterm labor have not been shown to be very effective?

In most countries, drugs registered for tocolysis are restricted to the $\beta$-adrenergicreceptor agonist ritodrine and the oxytocin receptor antagonist atosiban. The literature does not support the efficacy of magnesium sulfate and most authors call for discontinuation of the use of magnesium sulfate as a labor-inhibiting agent, which leaves only 
cyclo-oxygenase inhibitors and calcium channel blockers as off-license alternatives. ${ }^{8-10}$ The use of $\beta$-adrenergic-receptor agonists as first-line tocolytic agents has decreased due to the high incidence of maternal adverse effects. ${ }^{11,12}$ Concerns regarding adverse effects of cyclo-oxygenase inhibitors on the fetal kidneys and ductus arteriosus, the increased risk of neonatal intraventricular hemorrhage, and necrotizing enterocolitis associated with this treatment, have limited its use. ${ }^{13,14}$ When compared to $\beta$-adrenergic-receptor agonists, the oxytocin receptor antagonist atosiban has fewer maternal adverse effects with comparable efficacy (relative risk [RR] 1.07; 95\% confidence interval [CI] 0.98 to 1.17$).{ }^{12,15,16}$ However, atosiban has not been found to reduce the incidence of respiratory distress syndrome, a serious complication of prematurity, when compared to placebo. ${ }^{16}$ Calcium channel blockers appear to be more effective in postponing preterm delivery (RR 0.76 ; 95\% CI 0.59 to 0.99 ) and reducing neonatal respiratory distress (RR 0.64 ; CI 95\% 0.45 to 0.91 ) than $\beta$-adrenergic-receptor agonists. ${ }^{17,18}$ However, placebocontrolled nifedipine trials are not available.

Since the introduction of the oxytocin antagonist atosiban, the choice of first-line tocolytic drugs for the treatment of preterm labor is the subject of controversy in many papers. Some authors are concerned about the inconclusive information regarding the relative safety of calcium antagonists, such as nifedipine. ${ }^{19,20}$ Other authors question the tocolytic efficacy of atosiban, especially compared to nifedipine. ${ }^{17,21}$ This review discusses the available evidence to support a choice in type of first-line tocolytic drug, atosiban or nifedipine?

\section{Tocolytic efficacy}

The tocolytic efficacy of the oxytocin antagonist atosiban was established in 6 large randomized controlled doubleblind trials. ${ }^{12,15,22-25}$ Meta-analysis of these trials showed a small although significant increase in the proportion of women undelivered by 48 hours who had received atosiban compared to placebo (RR $1.13 ; 95 \%$ CI 1.02 to 1.26 ). ${ }^{16}$ However, this conclusion was not supported by a Cochrane meta-analysis by Papatsonis and co-workers. ${ }^{21}$ They found no differences between atosiban and placebo or between atosiban and $\beta$-adrenergic-receptor agonists in terms of tocolytic efficacy and neonatal outcomes.

Calcium channel blockers (CCB), registered as antihypertensive drugs, are used extensively for treatment of premature labor. In a Cochrane meta-analysis by King and colleagues, $\mathrm{CCB}$ were compared with mainly $\beta$-adrenergic-receptor agonists. ${ }^{17} \mathrm{CCB}$ reduced the number of women giving birth within 7 days after receiving treatment (RR 0.76; 95\% CI
0.60 to 0.97 ) and before 34 weeks of gestation (RR 0.83; 95\% CI 0.69 to 0.99$).{ }^{17}$ The results of this meta-analysis are based, for a large part, on one randomized controlled trial comparing nifedipine and ritodrine. ${ }^{18}$ Noticeably, this is the only large tocolytic trial to our knowledge presenting a reduction in neonatal respiratory distress syndrome. Whether this reduction is due to the tocolytic superiority of nifedipine remains uncertain. Nifedipine placebo-controlled trials have never been published. Large randomized controlled trials comparing atosiban and nifedipine directly are lacking.

However, 2 smaller studies comparing atosiban and nifedipine showed no differences in postponing preterm delivery. ${ }^{26,27}$ The first and largest, by Kashanian and colleagues, enrolled 80 women with preterm contractions between 26 and 34 weeks of gestation. Atosiban was effective in $82.5 \%$ of cases (not delivered within 48 hours) and nifedipine in $75 \%$, with a mean duration of pregnancy after treatment of 29 and 23 days $(P=0.79)$, respectively. Coomarasamy and colleagues published an indirect comparison method to analyze randomized controlled trials of nifedipine and atosiban by using $\beta$-adrenergic-receptor agonists as common comparator, with the preservation of the randomization process. ${ }^{28}$ The analysis showed no significant differences in efficacy in delaying delivery between nifedipine and atosiban. The limited evidence available suggests no large differences in tocolytic efficacy comparing atosiban and nifedipine; however, a direct comparison in a large powered randomized controlled trial is necessary to establish possible superiority of either tocolytic agent.

\section{Fetal effects}

Atosiban crosses the placenta in an average fetal versus maternal ratio of $0.124 .{ }^{29}$ Drug concentrations in the fetal circulation do not increase with longer infusion rates, suggesting that the drug does not accumulate in the fetus. ${ }^{29}$ Atosiban does not significantly alter maternal or fetal cardiovascular parameters when it is administered to late pregnant sheep. ${ }^{30}$ In chronically instrumented baboons during the last third of pregnancy, an atosiban infusion did not alter fetal oxygenation. ${ }^{31}$ The fetal concerns regarding the use of atosiban mostly discussed in literature are based on the results of the atosiban versus placebo trial by Romero and co-workers. ${ }^{23}$ They found a higher rate of fetal-infant deaths in the atosibantreated group compared to placebo. However, 7 of the 10 infant deaths were newborns with birth weights $<0.650 \mathrm{~kg}$ suggesting that extreme prematurity played a rather large role in these adverse outcomes. Romero and colleagues hypothesized that the anti-vasopressin effects of atosiban 
could have contributed to the poor outcome through possibly altered fetal responses to stress or insults. ${ }^{23,32}$ To date, evidence to support this hypothesis is lacking. Furthermore, the trials comparing atosiban with beta-agonists showed a comparable neonatal outcome. ${ }^{12,22}$

Nifedipine easily crosses the placenta with a fetal versus maternal ratio of 0.93 between umbilical cord blood and maternal serum concentrations. ${ }^{33,34}$ Some animal studies report changes in uterine blood flow and fetal acidosis after CCB administration. ${ }^{35-39}$ Harake and colleagues found decreased uterine blood flow and lower fetal arterial oxygen content in instrumented pregnant sheep treated with nifedipine infusion. ${ }^{35}$ However, in contrast, Holbrook and colleagues administered a single bolus of nicardipine to instrumented sheep and found no changes in uterine blood flow and fetal arterial oxygen content. ${ }^{36}$ They suggested that fetal acidosis after CCB infusion is primarily due to a decrease in uterine blood flow rather than a direct fetal effect of the drug. Blea and colleagues infused instrumented sheep with low dose nifedipine corresponding with human concentrations. ${ }^{37}$ They found hypoxia and acidosis in the sheep fetus without persistent decreases in uteroplacental or fetoplacental blood flows or blood pressures.

Most studies in humans show no decrease in uterine blood flow after nifedipine administration to pregnant women. ${ }^{38-42}$ Moretti and colleagues and Hanretty and colleagues found no changes in uterine and fetal Doppler flow velocity waveforms after oral nifedipine therapy in hypertensive pregnant women. ${ }^{38,40}$ Other studies have reported on normotensive women and the short-time effects (15 minutes, 1 hour, 3 hours and 5 hours) of oral nifedipine administration on fetal Doppler flow velocity waveforms. ${ }^{41-44}$ One study found a transient decrease in umbilical artery pulsatility index (PI) 15 minutes after $10 \mathrm{mg}$ sublingual nifedipine. ${ }^{43}$ The other studies found no changes in the fetal or uteroplacental circulation. ${ }^{41,42,44}$ Guclu and colleagues were the first to study fetal Doppler indices during 48 hours of nifedipine tocolysis. ${ }^{44}$ They found no changes in umbilical artery PI during treatment, although they did find decreased uterine artery PI and middle cerebral artery PI at 24 hours and 48 hours of treatment. We recently studied the direct effects of atosiban or nifedipine on fetal movement, fetal heart rate and fetal blood flow, yet found no effect of either tocolytic on the fetal biophysical profile. ${ }^{47}$ A Cochrane review of $\mathrm{CCB}$ for inhibiting preterm labor concluded that neonatal outcome was improved compared to beta-mimetics. ${ }^{17}$ Oei and coworkers followed up 48 children in utero exposed to nifedipine at 9 to 12 years of age. ${ }^{48}$ No negative effects on psychosocial and motor functioning were found.

\section{Maternal effects}

In comparison with $\beta$-adrenergic receptor agonists, atosiban and nifedipine showed less side effects. ${ }^{10,12,15,18}$ Most commonly reported adverse drug reactions (ADR) of atosiban in these studies were headache, vomiting and nausea, occurring in about $10 \%$ of the patients. Nifedipine exerts both vascular and cardiac effects. It vasodilates the vessels and exerts negative inotropic and chronotropic effects depressing the heart. ${ }^{45}$ The cardiodepressant effect of nifedipine in vivo is counteracted by a vasodilatation-triggered and baroreceptor mediated reflex increase in sympathic tone resulting in indirect cardiostimulation. The increase in sympathic tone compensates for the negative inotropic and chronotropic action by nifedipine on the heart. These mechanisms are most likely the basis for the ADR seen with nifedipine tocolysis. Most common ADR due to the vascular and cardiac effects of nifedipine are: hypotension; tachycardia; flushes; headache; increased liver enzymes; nausea and dizziness. ${ }^{46,47}$ Most of the randomized controlled trials on nifedipine for tocolysis have started with immediate-release tablets or capsules up to a maximum dose of $40 \mathrm{mg}$ during the first hour. The extended-release medication varied between studies from 60 to $160 \mathrm{mg}$ daily. ${ }^{10,18,46,48}$ These trials report only minor or no reductions in diastolic or systolic blood pressure in normotensive pregnant women during the tocolysis extended-release regimen. Two studies focusing on the short term effects of nifedipine in normotensive pregnant women found hypotension accompanied with tachycardia 45 minutes after nifedipine administration. ${ }^{41,49}$ Randomized studies of tocolytic drugs have generally been restricted to well-defined (low risk) populations, excluding multiple gestations, preterm premature rupture of membranes (PPROM), vaginal blood loss, maternal diabetes, or a history of cardiovascular disease. It is, therefore, difficult to translate these results to the general population of women with preterm labor. In recent years, several serious ADRs were published for women treated with CCB. ${ }^{20,50-59}$ Analysis of these case reports is hampered by the fact that it is uncertain whether these serious ADRs were solely due to $\mathrm{CCB}$ administration and/or to co-medication. Moreover, these cases provide no indication as to the incidence of these ADRs. To study the prevalence of serious maternal ADRs with the use of the various tocolytic drugs in a general population, we recently performed a prospective cohort study in the Netherlands and Belgium in a normal clinical setting. ${ }^{60}$ The participating hospitals registered, during one year, consecutive women who were treated with tocolytic drugs for preterm labor. In this period, 1920 women were treated with tocolytic drugs. Twenty-eight cases fulfilled the 
study definition of an ADR; 14 cases were categorized as serious ADR and 14 as mild ADR. Serious ADR consisted of severe dyspnea $(n=6)$, hypotension $(n=4)$, lung edema $(n=2)$, hypoxia $(n=1)$ and cardiac failure $(n=1)$. The overall incidence of serious ADR was relatively low (0.7\%). In 1327 women treated with a single tocolytic drug the incidence of serious ADR was $1.7 \%$ for betamimetic drugs and $0.9 \%$ for nifedipine; no serious ADR were registered with the use of a single course of atosiban. When compared to atosiban, the number needed to prevent one serious ADR for $\beta$-adrenergic receptor agonists was 59 (95\% CI lower limit 35) and the number needed to prevent one serious ADR for nifedipine was 109 (95\% CI lower limit 56).

When combined courses (ie, when a patient was treated with multiple tocolytic drugs at the same time) were given in $16.2 \%$ of all patients the incidence of severe ADR was high (1.6\% to $2.5 \%$ ). The study also showed 4 ADRs in women with a multiple gestation $(n=414)$, in 2 women receiving a single course of nifedipine and in 2 women treated with combined courses; However, these incidences were not statistically significant. Whether this was due to lack of statistical power is uncertain.

Our study confirmed the high rate of ADR of $\beta$-adrenergicreceptor agonists. Furthermore, the use of combined courses of tocolytics led to a high rate of serious ADR. We found no serious ADR after a single course treatment with atosiban. The overall incidence of serious ADR with the use of a single course nifedipine was relatively low in singleton pregnancies, although serious ADR did occur with this medication.

\section{Conclusion}

Tocolytic drugs have not been shown to be very effective or to improve fetal outcome. However, tocolysis is applied with the aim of postponing delivery for 48 hours, to allow for maximal effect of maternal parenteral steroid administration and transportation of the mother to a center with NICU facilities. The choice of the first-line tocolytic agent in terms of safety, effectiveness and costs is a topic of debate. An ideal tocolytic should postpone delivery without maternal and fetal side effects at low costs. Unfortunately, none of the tocolytics described above fulfils all these criteria. In this review we focused on the oxytocin antagonist atosiban and the calcium antagonist nifedipine. Although nifedipine crosses the placenta easily, no human studies have shown any adverse fetal or neonatal effects to date. The overall incidence of maternal serious adverse tocolytic drug reactions with the use of a single course nifedipine (not combined with other tocolytic drugs) in singleton gestation appears to be low, but not absent. The oral route of administration, low costs and a possible efficacy in reducing neonatal morbidity (shown in one large study) favor the use of CCBs. Atosiban has the best maternal and fetal safety profile; however, its costs are considerable. Many large randomized (placebo) controlled trials are available suggesting tocolytic efficacy but a reduction in neonatal morbidity was never found.

A direct comparison between oxytocin antagonists and CCBs in terms of tocolytic efficacy and effects on neonatal outcome is necessary. Moreover, larger studies with different nifedipine dose regimens are necessary to compare efficacy and maternal side effects.

\section{Disclosures}

RDH and GHAV performed and published a prospective cohort study on tocolysis in 2009 which was supported by an unconditional grant from Ferring Pharmaceuticals.

\section{References}

1. Slattery MM, Morrison JJ. Preterm delivery. Lancet. 2002;360: 1489-1497.

2. Hack M, Dandruff AA. Outcomes of children of extremely low birthweight and gestational age in the 1990's. Early Hum Dev. 1999 (vol 53).

3. Petrou S, Mehta Z, Hockley C, Cook-Mozaffari P, Henderson J, Goldacre M. The impact of preterm birth on hospital inpatient admissions and costs during the first 5 years of life. Pediatrics. 2003;112: $1290-1297$.

4. Hoyert DL, Mathews TJ, Menacker F, Strobino DM, Guyer B. Annual summary of vital statistics: 2004. Pediatrics. 2006;117:168-183.

5. Langhoff-Roos J, Kesmodel U, Jacobsson B, Rasmussen S, Vogel I. Spontaneous preterm delivery in primiparous women at low risk in Denmark: population based study. BMJ. 2006;332:937-939.

6. Crowley P. Prophylactic corticosteroids for preterm birth. Cochrane Database Syst Rev. 2000:CD000065.

7. Simhan HN, Caritis SN. Prevention of preterm delivery. N Engl J Med. 2007;357:477-487.

8. Grimes DA, Nanda K. Magnesium sulfate tocolysis: time to quit. Obstet Gynecol. 2006;108:986-989.

9. King J, Flenady V, Cole S, Thornton S. Cyclo-oxygenase (COX) inhibitors for treating preterm labor. Cochrane Database Syst Rev. 2005:CD001992.

10. King JF, Flenady VJ, Papatsonis DN, Dekker GA, Carbonne B. Calcium channel blockers for inhibiting preterm labor. Cochrane Database Syst Rev. 2002:CD002255.

11. Anotayanonth S, Subhedar NV, Garner P, Neilson JP, Harigopal S. Betamimetics for inhibiting preterm labor. Cochrane Database Syst Rev. 2004:CD004352.

12. Effectiveness and safety of the oxytocin antagonist atosiban versus beta-adrenergic agonists in the treatment of preterm labor. The Worldwide Atosiban versus Beta-agonists Study Group BJOG. 2001;108:133-142.

13. Major CA, Lewis DF, Harding JA, Porto MA, Garite TJ. Tocolysis with indomethacin increases the incidence of necrotizing enterocolitis in the low-birth-weight neonate. Am J Obstet Gynecol. 1994;170: $102-106$.

14. Norton ME, Merrill J, Cooper BA, Kuller JA, Clyman RI. Neonatal complications after the administration of indomethacin for preterm labor. N Engl J Med. 1993;329:1602-1607. 
15. French/Australian Atosiban Investigators Group. Treatment of preterm labor with the oxytocin antagonist atosiban: a double-blind, randomized, controlled comparison with salbutamol. Eur J Obstet Gynecol Reprod Biol. 2001;98:177-185.

16. Coomarasamy A, Knox EM, Gee H, Khan KS. Oxytocin antagonists for tocolysis in preterm labor - a systematic review. Med Sci Monit. 2002;8:RA268-RA273.

17. King JF, Flenady VJ, Papatsonis DN, Dekker GA, Carbonne B. Calcium channel blockers for inhibiting preterm labor. Cochrane Database Syst Rev. 2003:CD002255.

18. Papatsonis DN, Van Geijn HP, Ader HJ, Lange FM, Bleker OP, Dekker GA. Nifedipine and Ritodrine in the management of preterm labor: a randomized multicenter trial. Obstet Gynecol. 1997;90: 230-234

19. Oei SG. Calcium channel blockers for tocolysis: a review of their role and safety following reports of serious adverse events. Eur J Obstet Gynecol Reprod Biol. 2006;126:137-145.

20. van Geijn HP, Lenglet JE, Bolte AC. Nifedipine trials: effectiveness and safety aspects. BJOG. 2005;(112 Suppl 1):79-83

21. Papatsonis D, Flenady V, Cole S, Liley H. Oxytocin receptor antagonists for inhibiting preterm labor. Cochrane Database Syst Rev. 2005: CD004452.

22. Moutquin JM, Sherman D, Cohen H, et al. Double-blind, randomized, controlled trial of atosiban and ritodrine in the treatment of preterm labor: a multicenter effectiveness and safety study. Am J Obstet Gynecol. 2000;182:1191-1199.

23. Romero R, Sibai BM, Sanchez-Ramos L, et al. An oxytocin receptor antagonist (atosiban) in the treatment of preterm labor: a randomized, double-blind, placebo-controlled trial with tocolytic rescue. Am J Obstet Gynecol. 2000;182:1173-1183.

24. Goodwin TM, Paul R, Silver H, et al. The effect of the oxytocin antagonist atosiban on preterm uterine activity in the human. Am J Obstet Gynecol. 1994;170:474-478.

25. Goodwin TM, Valenzuela GJ, Silver H, Creasy G. Dose ranging study of the oxytocin antagonist atosiban in the treatment of preterm labor. Atosiban Study Group Obstet Gynecol. 1996;88: 331-336.

26. Al-Omari WR, Al-Shammaa HB, Al-Tikriti EM, Ahmed KW. Atosiban and nifedipine in acute tocolysis: a comparative study. Eur J Obstet Gynecol Reprod Biol. 2006;128:129-134.

27. Kashanian M, Akbarian AR, Soltanzadeh M. Atosiban and nifedipin for the treatment of preterm labor. Int J Gynaecol Obstet. 2005; 91:10-14.

28. Coomarasamy A, Knox EM, Gee H, Song F, Khan KS. Effectiveness of nifedipine versus atosiban for tocolysis in preterm labor: a metaanalysis with an indirect comparison of randomised trials. BJOG. 2003;110:1045-1049.

29. Valenzuela GJ, Craig J, Bernhardt MD, Holland ML. Placental passage of the oxytocin antagonist atosiban. Am J Obstet Gynecol. 1995;172:1304-1306.

30. Greig PC, Massmann GA, Demarest KT, Weglein RC, Holland ML, Figueroa JP. Maternal and fetal cardiovascular effects and placental transfer of the oxytocin antagonist atosiban in late-gestation pregnant sheep. Am J Obstet Gynecol. 1993;169:897-902.

31. Nathanielsz PW, Honnebier MB, Mecenas C, Jenkins SL, Holland ML, Demarest K. Effect of the oxytocin antagonist atosiban (1-deamino-2-D-tyr(OET)-4-thr-8-orn-vasotocin/oxytocin) on nocturanl myometrial contractions, maternal cardiovascular function, transplacental passage, and fetal oxygenation in the pregnant baboon during the last third of gestation. Biol Reprod. 1997;57: 320-324.

32. Gomez R, Romero R, Ghezzi F, Yoon BH, Mazor M, Berry SM. The fetal inflammatory response syndrome. Am J Obstet Gynecol. 1998;179:194-202.

33. Manninen AK, Juhakoski A. Nifedipine concentrations in maternal and umbilical serum, amniotic fluid, breast milk and urine of mothers and offspring. Int J Clin Pharmacol Res. 1991;11:231-236.
34. Ferguson JE 2nd, Dyson DC, Schutz T, Stevenson DK. A comparison of tocolysis with nifedipine or ritodrine: analysis of efficacy and maternal, fetal, and neonatal outcome. Am J Obstet Gynecol. 1990;163: $105-111$.

35. Harake B, Gilbert RD, Ashwal S, Power GG. Nifedipine: effects on fetal and maternal hemodynamics in pregnant sheep. Am J Obstet Gynecol. 1987; 157:1003-1008.

36. Holbrook RH Jr, Voss EM, Gibson RN. Ovine fetal cardiorespiratory response to nicardipine. Am J Obstet Gynecol. 1989;161:718-721.

37. Blea CW, Barnard JM, Magness RR, Phernetton TM, Hendricks SK. Effect of nifedipine on fetal and maternal hemodynamics and blood gases in the pregnant ewe. Am J Obstet Gynecol. 1997;176: 922-930.

38. Moretti MM, Fairlie FM, Akl S, Khoury AD, Sibai BM. The effect of nifedipine therapy on fetal and placental Doppler waveforms in preeclampsia remote from term. Am J Obstet Gynecol. 1990;163: 1844-1848.

39. Lindow SW, Davies N, Davey DA, Smith JA. The effect of sublingual nifedipine on uteroplacental blood flow in hypertensive pregnancy. $\mathrm{BrJ}$ Obstet Gynaecol. 1988;95:1276-1281.

40. Hanretty KP, Whittle MJ, Howie CA, Rubin PC. Effect of nifedipine on Doppler flow velocity waveforms in severe pre-eclampsia. $B M J$. 1989;299:1205-1206.

41. Pirhonen JP, Erkkola RU, Ekblad UU, Nyman L. Single dose of nifedipine in normotensive pregnancy: nifedipine concentrations, hemodynamic responses, and uterine and fetal flow velocity waveforms. Obstet Gynecol. 1990;76:807-811.

42. Mari G, Kirshon B, Moise KJ Jr, Lee W, Cotton DB. Doppler assessment of the fetal and uteroplacental circulation during nifedipine therapy for preterm labor. Am J Obstet Gynecol. 1989;161:1514-1518.

43. Rizzo G, Arduini D, Mancuso S, Romanini C. Effects of nifedipine on umbilical artery velocity waveforms in healthy human fetuses. Gynecol Obstet Invest. 1987;24:151-154.

44. Guclu S, Saygili U, Dogan E, Demir N, Baschat AA. The short-term effect of nifedipine tocolysis on placental, fetal cerebral and atrioventricular Doppler waveforms. Ultrasound Obstet Gynecol. 2004;24:761-765.

45. Scholz H. Pharmacological aspects of calcium channel blockers. Cardiovasc Drugs Ther. 1997;(10 Suppl 3):869-872.

46. Papatsonis DN, Lok CA, Bos JM, Geijn HP, Dekker GA. Calcium channel blockers in the management of preterm labor and hypertension in pregnancy. Eur J Obstet Gynecol Reprod Biol. 2001;97:122-140.

47. Cararach V, Palacio M, Martinez S, et al. Nifedipine versus ritodrine for suppression of preterm labor Comparison of their efficacy and secondary effects. Eur J Obstet Gynecol Reprod Biol. 2006;127(2):204-208.

48. Oei SG, Mol BW, de Kleine MJ, Brolmann HA. Nifedipine versus ritodrine for suppression of preterm labor; a meta-analysis. Acta Obstet Gynecol Scand. 1999;78:783-788.

49. Ferguson JE 2nd, Dyson DC, Holbrook RH Jr, Schutz T, Stevenson DK. Cardiovascular and metabolic effects associated with nifedipine and ritodrine tocolysis. Am J Obstet Gynecol. 1989;161:788-795.

50. Gatault P, Genee O, Legras A, Garot D, Mercier E, Fichet J. CalciumChannel Blockers: An increasing cause of pulmonary edema during tocolytic therapy. Int J Cardiol. 2008;130(3):e123-e124.

51. Hodges R, Barkehall-Thomas A, Tippett C. Maternal hypoxia associated with nifedipine for threatened preterm labor. BJOG 2004;111:380-381.

52. Bal L, Thierry S, Brocas E, Adam M, Van de Louw A, Tenaillon A. Pulmonary edema induced by calcium-channel blockade for tocolysis. Anesth Analg. 2004;99:910-911.

53. Vaast P, Dubreucq-Fossaert S, Houfflin-Debarge V, et al. Acute pulmonary oedema during nicardipine therapy for premature labor; Report of five cases. Eur J Obstet Gynecol Reprod Biol. 2004;113:98-99.

54. Oei SG, Oei SK, Brolmann HA. Myocardial infarction during nifedipine therapy for preterm labor. $N$ Engl J Med. 1999;340:154.

55. Verhaert D, Van Acker R. Acute myocardial infarction during pregnancy. Acta Cardiol. 2004;59:331-339. 
56. Parasuraman R, Gandhi MM, Liversedge NH. Nifedipine tocolysis associated atrial fibrillation responds to DC cardioversion. BJOG. 2006;113:844-845.

57. van Veen AJ, Pelinck MJ, van Pampus MG, Erwich JJ. Severe hypotension and fetal death due to tocolysis with nifedipine. BJOG. 2005;112:509-510.

58. Abbas OM, Nassar AH, Kanj NA, Usta IM. Acute pulmonary edema during tocolytic therapy with nifedipine. Am J Obstet Gynecol. 2006;195:e3-e4.
59. Nassar AH, Ghazeeri G, Usta IM. Nifedipine-associated pulmonary complications in pregnancy. Int J Gynaecol Obstet. 2007;97: 148-149.

60. de Heus R, Mol BW, Erwich JJ, et al. Adverse drug reactions to tocolytic treatment for preterm labor: prospective cohort study. $B M J$. 2009;338:b744.

\section{Publish your work in this journal}

The International Journal of Women's Health is an international, peerreviewed open-access journal publishing original research, reports, reviews and commentaries on all aspects of women's healthcare including gynecology, obstetrics, and breast cancer. Subject areas include: Chronic conditions (migraine headaches, arthritis, osteoporosis);
Endocrine and autoimmune syndromes; Sexual and reproductive health; Psychological and psychosocial conditions. The manuscript management system is completely online and includes a very quick and fair peer-review system. Visit http://www.dovepress.com/ testimonials.php to read real quotes from published authors. 